\title{
The Road to Positive Health
}

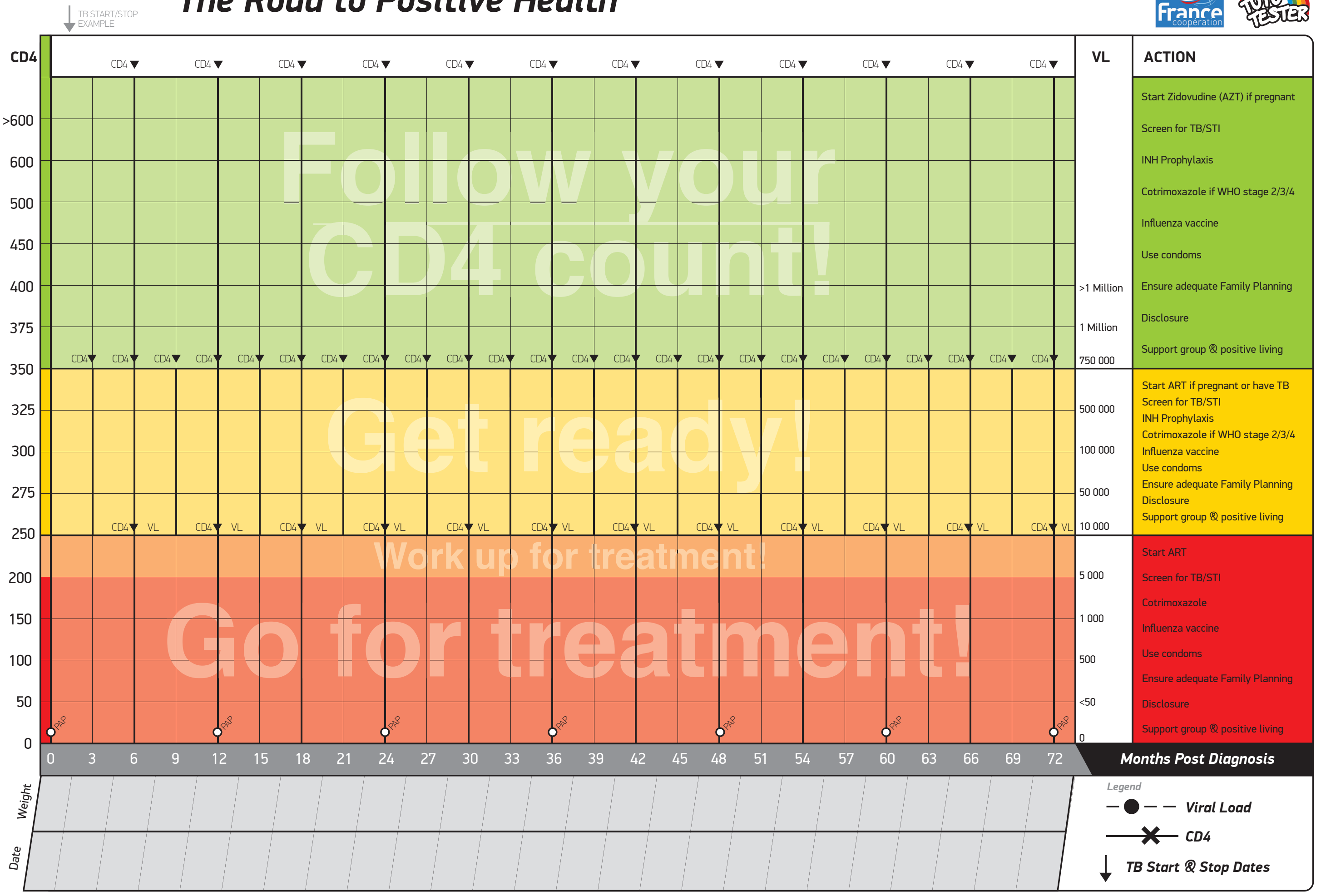


Name:

Date Of Birth:

Address:

\section{Clinic:}

Folder Number:

Date of HIV test:

Date Cotrimoxazole started:

Date ART Commenced:

\begin{tabular}{|l|l|l|}
\hline Medication & Date Started & Date Stopped \\
\hline & & \\
\hline & & \\
\hline & & \\
\hline & & \\
\hline & & \\
\hline & & \\
\hline & & \\
\hline & & \\
\hline & & \\
\hline
\end{tabular}

IMPORTANT HEALTH EVENTS, OPPORTUNISTIC INFECTIONS, HOSPITALIZATIONS

Event

Date

\section{Date \\ Appointments}

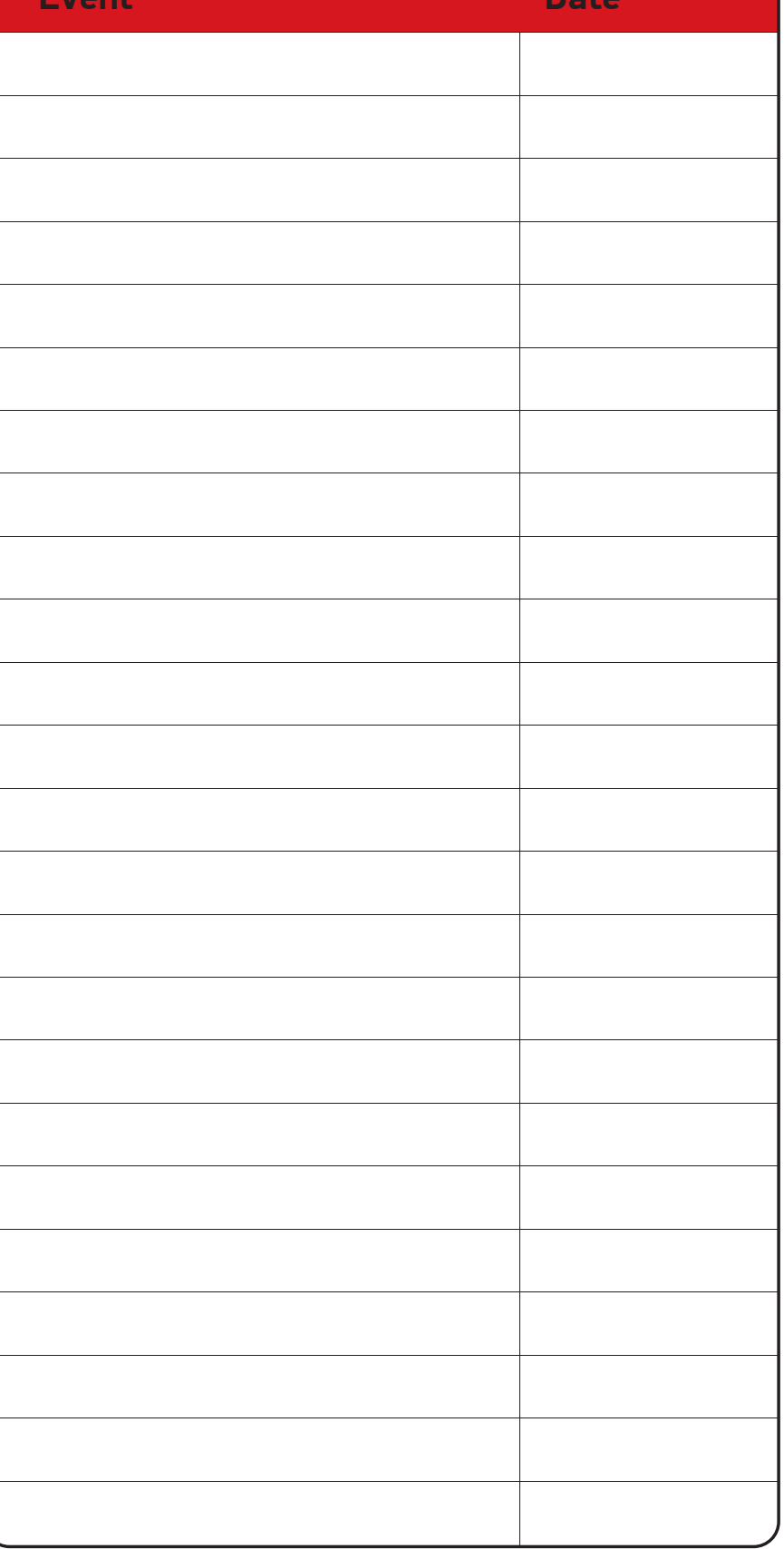

